\title{
The Perceived Supervisor and Organizational support on Organizational Climate
}

\author{
${ }^{1}$ James Gachahi Wangombe, ${ }^{2}$ Tabitha Wangare Wambui, ${ }^{3}$ Alice Wangui Kamau \\ ${ }^{1,2,3}$ Lecturer Human Resource Department School of Business Karatina University, Kenya
}

\begin{abstract}
Organizational Climate Was Viewed To Be Comprised Of Qualities That Discriminate One Firm From Another, That Endure Overtime And Help To Control Actions Of Employees Within The Organization (Forehand And Von Gilmer, 1964).Approximately 50 To 70 Percent Of An Organization's Climate Can Be Traced To Its Leadership Or Management Style. Perceived Organization Support (Pos) Can Be Positive If Reciprocation Of Support And Respect Occurs Between Employer And Employee. If The Reciprocation Does Occur And The Employee Feels That He Or She Is Being Appreciated And Respected For The Work That He Or She Is Doing, The Pos Is Increased(Dean, 1996).If The Respect And Appreciation Is Either Not Present Or Is Not Expressed Adequately, Then The Employee May Begin To Harbor Suspicion, Which May Increase Organizational Cynicism (Eisenberger, 1986). Organizational Commitment May, At That Point, Be Lessened; Thus Jeopardizing The Stability Of The Organization. Reciprocation Can Include A Wide Array Of Things, Such As Pleasing Pay And Benefits, A Promotion, Mutual Respect Between Employer And Employee (Levy, 2013). Good Climate Has Been Correlated With Desirable Outcomes Like Job Satisfaction, Confidence In Management, Effective Commitment, Intention To Quit, Emotional Exhaustion, Faith In Organizational And Performance. It Is Also Linked With Desirable Behaviors Like, Risk-Taking (Strategic), Departure From The Status Quo, Open Communication, Trust, Operational Freedom And Employee Development (Levy,2013). This Reviewed Literature Has Been Put Together For Easy Access To Public At Large
\end{abstract}

\section{Introduction}

Organizational climate was viewed to be comprised of qualities that discriminate one firm from another, that endure overtime, and help to control actions of employees within the organization (Forehand and Von-Gilmer, 1964). Climate is a subcomponent of organizational culture (Schein, 1992; Stringer, 2002).Tagiuri, Litwin, and Barnes (1968) build upon Forehand and Von Gilmer assertions and added the notion that climate is a set of qualities that encompass the organization of inquiry. Organizational climate is the general perception of the working conditions of an enterprise, including the level of motivation, innovation, trust, conflict, morale, rewards equity, leader credibility, and resistance to change. Organizational climate develops over many years and is affected by many factors and therefore cannot change overnight. A 'good' climate is not only keep people comfortable, but is also strategically advantageous to the organization while also bringing out the best in its stakeholders because they are in a motivational climate (Levy, 2013).

Organizational climate also represents organizational values sensed by employees (Schneider, 1990) and the messages are sent from the environment of the organization to the perception of each individual member. These messages convey the organizations' expectations for employees 'behaviors and imply the possible consequences linked to these behaviors. Therefore, employees of an organization develop self-expected work behaviors based on this information, Schneider, et al., (2005). Employees detect how much the organization values their services based on organizational strategies and open communication displayed. Management should develop a sense of trust, leadership credibility, rewards integrity, and employee empowerment to attract warm organization climate. Organizational Climate is shaped by various factors which include; motivation which is the desire to pursue a goal together with the energy to stay committed even when challenges and barriers set in. Another factor is Change which is the willingness to innovate and adapt in a dynamic environment.

Teamwork on the other hand describes the collaborative interactions in pursuit of the goal that require both a sense of shared purpose and the right tools to be able to work and communicate as a team(Levy,2013).There are shared values and learning on each other to achieve great things for the organization and ourselves.

1. Execution: Denoting the ability to achieve strategic results by implementing effective tactics and keeping to a schedule is also key in shaping the organization climate. Plans are as good as not having them if they cannot be implemented. 
2. Trust: Which describe the belief in the reliability, truth, ability, and strength of the words and matching them with deeds of members of the organization facilitates necessary risk taking to achieve success in the other climate factors.

Good climate has been correlated with desirable outcomes like Job satisfaction, Confidence in management, affective commitment, intention to quit, emotional exhaustion, faith in organizational and performance. It is also linked with desirable behaviors like, risk-taking (strategic), departure from the status quo, open communication, trust, operational freedom, and employee development(Levy,2013).

In contrast bad climate has been linked to turnover, stress, sickness, poor performance, error rate, wastage, accidents and the correlative of bad behaviors like, sabotage, absenteeism, go-slow and, bullying.

The two conditions elicit different outcomes at the workplace. Bad climate bring forth, fear, crisis, anxiety, aggression, burnouts, turnover, politicking, hopelessness and stagnation among many others. On the other hand good climate bears respect, support, entrepreneurship, innovations, cooperation, high performance, profitable management practices, knowledge management and sharing, learning organization, readiness to change and openness.

\section{Conceptual Framework}

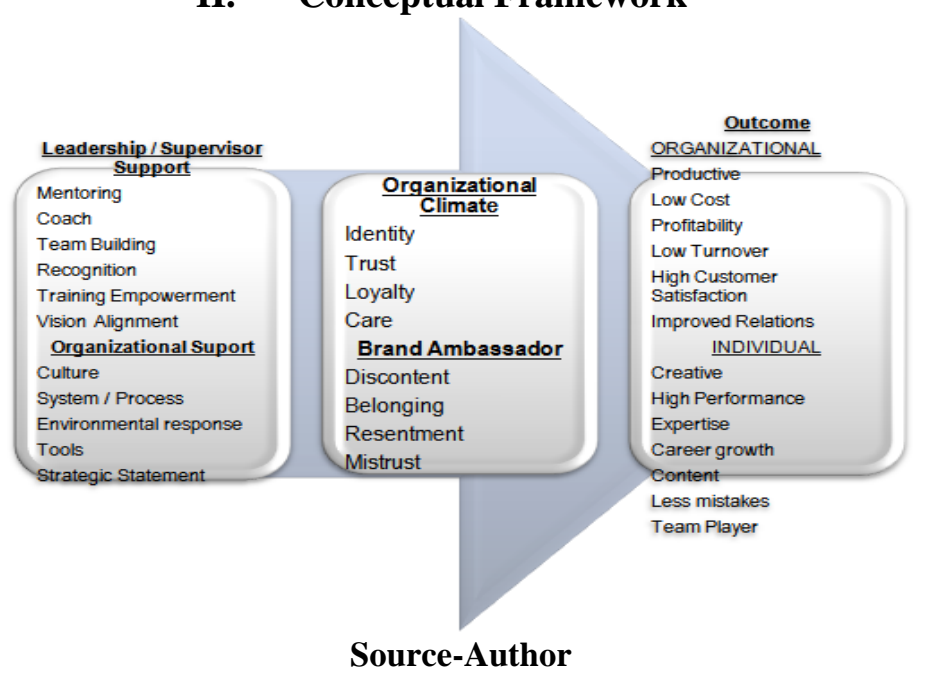

Organization climate can improve through perceived organizational support and supervisor support (Michele, 2010).

Perceived Organizational Support effect to Organization climate

Organizational climate is the general perception of the working conditions of an enterprise, including the level of motivation, innovation, trust, conflict, morale, rewards equity, leader credibility, and resistance to change. Organizational climate develops over many years and is affected by many factors and therefore cannot be changed by simply dusting off the top layer of discontent. Just as the most effective cleaning begins at the top and progresses downward, so must the measures that will make sweeping changes to the overall perception of the business. Michele (2011). Organization support in the following key areas can bear fruits of positive climate.

\section{a. Motivation Begins with Decluttering the Workspace}

Perceived organization support through motivation of workers, workplace decluttering can make significant progress to improving the organizational climate. For example of workers desks are overflowing with paper, digitalize/automate the organization records. This will reinstate workers motivation as they easily access information with little effort. Michele (2011)

\section{b. Implement rewards equity to motivate employees}

Once you have removed the clutter as an obstacle to increasing productivity, the next step is to determine and implement policies that will motivate employees. As many theories regarding what motivates employees posits, workers respond differently when presented a list of performance incentives Maslow hierarchy of needs comes in to play. However, all workers will be more motivated if they believe there is rewards equity within the organization.

Eliminating the chances of favoritism, discrimination, nepotism, lack transparency and recognizing achievements that are not necessarily high profile will significantly boost the morale of workers. This will elicit a positive organization climate. Michele (2011) 


\section{c. Embrace Innovation and the Entrepreneurial Spirit-Supervisors}

The organization should strive to make workers job in to entrepreneurial experience. The answer is yes, but it will take some creative thinking and the willingness of managers to relinquish some control. Creating an entrepreneurial spirit begins with transforming workers into the economic engines of the company. One way to facilitate entrepreneurship is to set up each department or team as a profit center and allow them to keep any profits generated through savings or increased sales. The company can offer individuals in-house patents for innovative ideas and pay a royalty for the savings or revenues generated from the patented idea or have inter department innovation competitions and reward the best innovators Michele (2011).

\section{d. Prepare Workers to Embrace Change}

It is so important that change becomes an integral part of the organization's culture. This will reduce resistance to change. Organizations should review and institute new procedures and processes annually. If change is on everyone's seasonal calendar, it will not take anybody by surprise.

\section{e. Create a Sense of Purpose}

Organizational climate is enhanced when coworkers feel a connection or bond with their colleagues. Even if each employee has a different job within the organization, there needs to be a unifying, core purpose in what they do that is tied back to the organization as a whole. However, they are all connected to the unifying purpose of having a profitable and socially responsible firm. Connecting the dots, like the NASA objective of taking a man to the moon, so employees understand and visibly see how their work is related to the broader picture will do wonders for morale. Strategic statements should help in netting the workers together. Management should develop a sense of trust, leadership credibility, rewards integrity, and employee empowerment to attract warm organization climate.

\section{g. Provide the Right Tools for Effective Collaboration}

It is known that teamwork depends on the ability to effectively collaborate with one's coworkers in an environment best-suited for the exchange of information. Organization should provide an enabling environment for collaboration, meeting rooms, creative centres, collaborative soft wares and team building sessions can help build a positive climate.

\section{h. Empower Employees for Better Execution}

Employees want to feel that their work is valuable and they have some control in the final product. Organization support through empowerment leads to better execution because employees who are closest to the work product are able to address problems faster and have more ideas on how to improve efficiency. This can it generally create positive perceptions of the employer/employee relationship within the organization. Empowerment will give an organization that fresh scent of a good climate.

\section{i. Find Periodic Downtime to Improve Execution}

It may sound counter-intuitive to take a breath to improve execution. Signaling a stop to evaluate and refocus is health for a positive climate. This will reduce burnouts either mentally or physically.

\section{j. Be honest in communications to build Trust}

Ensuring, the organization communicates clearly and often to the employees about the true state of affairs, including the mission, goals, financial position, achievements and missteps of the organization. No one likes bad news, but trust will never flourish in an organization that refuses to air its dirty laundry. Keeping workers in the dark about the true financial health of the company only creates rumor-mongering.

\section{k. Managers should Promote Ethical Behavior}

High performance teams cannot be maintained in an atmosphere of unethical behavior. Organizations should foster trust through ethics to give guiding principle and consequences of non-compliance. There are several practices that build trust at both the individual and organizational level. Personnel procedures that produce the desired ethical behaviors and swiftly disciplines those who step outside these boundaries should be kept in play. Plants with the most favorable working environment are also the most profitable. The atmosphere of a workplace makes a difference to organization performance which manifest in profitability, coherence, societal support and stakeholders.

Organizational climate refers to an organization's policies, procedures, and practices commonly perceived by the members of the organization (Schneider, 1990). That is, employees form a subjective awareness based on collective experiences in the organization and this subjective awareness is referred to as the "climate" of the organization (Schneider and Bowen, 1995).Organizational climate refers to the organization's 
support for employees' activities, work procedures, and behaviors as sensed by employees in all aspects of customer services (Schneider et al., 1998).For example when employees sense that they will be rewarded for providing quality services to customers, and the organization implements service activities to support them, the organizational climate is thus formed (Schneider and Bowen, 1985).Customers are also able to feel the organization's organizational climate through their interactivities with the client service teams (Schneider, 1980, 1990).This customers' awareness of the organizational climate further positively affects their opinions and level of satisfaction to the company quality of the services(Bitner et al., 1990; Parasuraman, 1987; Kao, 2008).

Thus, an organization must create and maintain a positive organizational climate that suits the attributes of the services it offers if the organization wishes to achieve the image of service excellence (Schneider and Bowen, 1992). Organizational climate creates a cyclical system of positive feedback. Employees in a high organizational climate environment care highly about customers' opinions on their services and tend to think about how to improve their services and maximize customer satisfaction. These employees have higher tendency to show positive service/work experiences. Customers who benefit by such positive experiences also tend to give employees positive opinions. This positive feedback, in turn, encourages employees to strive for even better services in the next opportunity to serve a customer (Katz and Kahn, 1978).

These companies are supposedly spending large amounts of resources to create a positive environment for their employees. Firms offer many varying types of tangible and intangible items to their workers in order to achieve some sense of positive attitude toward/about the organization. These tangible and intangible items that are received can be seen as creating different facets of the culture of the organization. These facets include supportive climate, ethical climate, social climate, and trusting climate. In order to create a supportive climate, companies provide things such as profit sharing, tuition reimbursement, flextime for mothers of young children, and receiving personal communication from the CEO. For ethical climate, firms provide compensation for community volunteer work, and provide an ombudsperson to help resolve conflicts within the workplace In many organizations the HR is the ombudsman,. In creating a social culture, companies have flattened their organizational. All people have access to upper management and promote monthly celebrations for things like birthdays and company financial successes (Levering and Markowitz, 2007). Finally, companies creating trusting climates have created transparent policies and allowed workers to participate in religious/cultural activities. It should be duly noted that these tangible and intangible items companies give to and allow of their workers cost time, money, and non-renewable resources.

Therefore, it is critical that we understand whether these climate variables indeed create enough positive people psychological and behavioral outcomes to warrant their continuance.

The idea of organizational climate integrates at least three types of concepts. They include Environmental concepts, such as size and arrangement of the firm, which are peripheral to the person, Individual concepts, such as attitudes the worker brings with him to the firm, Outcome concepts including such things as satisfaction, performance, and commitment to the firm, which are determined by the interaction between the environmental and individual concepts. The importance of investigating the interaction of organizational and individual variables is that it provides much needed direction for identifying and conceptualizing environmental variables relevant to the climate.

\section{Other organization climate variables}

Organizational climate variables such as participation, feelings of trust, and performance can provide useful insight for refining work environments (James and James, 1989).climate impacts employee attitudes and motivation which, in turn, has a direct impact on business performance (Stringer, 2002).

A firm's climate is only understood as they are perceived by the members of the organization, and thus, we must allow these organizational members to utilize the firm's climate to filter phenomena to those employees (Litwin \& Stringer, 2002). Climate is rooted in the person-environment fit theories from Lewin (1951) whereby behavior is a product of both the person and the environment while culture assumes that the employee cannot be divided from the environment when employees sense that they are valued and supported by the organization, they think they have a duty and obligation to act for achievement of the organization's goal, as a gesture to repay the organization's support (Wayne et al., 1997). Work environment characterized by positive organizational climate does not bring direct spill-over effect to the interactive relationships between the employees and the customers. Organizational climate only has moderating effects on the relationships between organizational support and loyalty/service delivery-related service-oriented organizational citizenship behaviors. No moderating effect is found in the relationship between organizational support and participation-related service oriented organizational citizenship behaviors.

If organizations in the service industries expect client contact employees to put in extra effort in customer service, it is necessary to care more for employees' welfare and value employees' contributions beyond the basic needs and assistance. When organizational climate is formed in an organization, the management should consider how to reinforce employees' voluntary participation in the organization's service 
activities on top of building employee loyalty and encouraging performance of service delivery-related service oriented organizational citizenship behaviors (Wayne et al., 1997).Organizational climate has partial effect on the relationship between employee-perceived organizational support and service-oriented organizational citizenship behaviors and has no effect to the factor of participation related service behaviors (Wayne et al., 1997).

Timely confirmation on employees' work performance, high focus on employees' welfare, attention to employees' health and family, and timely assistances are all practices that help to create a perception of giving which in turn motivates employees to repay the organization for its care and empathy through extra-role behaviors. Open and regular announcements of benefit or assistance policies, i.e. offering a complete plan of career path, professional service training, or open channel of promotion, are also effective in conveying the organization's determination to support its employees. This in turn builds employees' trust in and identification to the organization.

According to Eisenberger et al. (1986), organization support (OS) perceived by employees refers to how much an organization cares about the welfare of its employees and how much it values the employees' contributions to the business. When employees construe that their organization trusts and values them, a sense of obligation sets in, and they reciprocate by working hard towards the organization's goals, as a payback for the organization's recognition of their values. Organizational support satisfies employees 'social emotional needs. When employees feel respected, cared for, and accepted, teamwork is improved and role identification reinforced. The belief, that an employee will be rewarded for working hard catapult higher organizational performance, job satisfaction, and organizational commitment, and reduces employee turnover (Rhoades and Eisenberger, 2002).This belief of organizational support also improves employees' voluntary citizenship behaviors because the basis of social exchange is founded on the trust and goodwill built up in between the two parties of exchange. (Eisenberger et al., 1986, 1990; Rhoades and Eisenberger, 2002; Shore and Wayne, 1993; Yoon and Suh, 2004).Employer and employee relationship develops and both parties develop rights and obligations that go beyond the call of duty.

From the perspective of employer/ employee relationship, when a positive relationship exists between the employer and employees, organizational support not only motivates employees to take their work seriously but also attracts a sense of belonging or emotional identification towards the organization. Employees may even voluntarily engage in activities that are beneficial to the organization without asking for tangible rewards (Eisenberger et al., 1990). They voluntarily participate in the growth of the firm and these voluntary behaviors are exactly manifestation of OCBs (Wayne et al. (1997).According to Van Dyne et al., 1994, Organization support reinforces employees acceptance to internal/external adaptation of the organizational values e.g. that is, customer first. Employees may become even more devoted in the performance of in-role and extra-role work behaviors to improve customer services as well as the organizations over all images. In the aspect of loyalty citizenship behaviors, organization support represents certain socio-economic rewards and such rewards oblige employees to display loyalty behaviors (Graham, 1991).

Therefore, the more OS felt by employees, the more likely they would push the sale the products or services to customers as well as representing a positive image for the company (Bowen and Schneider, 1988). With the view to repay the organization's support, which arises from a mutual-benefiting relationship, employees tend to proactively participate in management and development of the business (Rhoades and Eisenberger, 2002).Client service employees accurately relays information to the management relating to customers' needs, as well as relevant suggestions for improvements, based on their everyday experience with customers (Bettencourt et al., 2001). When employees view mutual trust from the employer, they develop higher willingness to quickly respond to customers 'needs with a courteous service attitude. It is essential for an organization to care, motivate and respect its employees, as well as to boost employees' confidence and make them feel there is a supportive organizational climate. The organization can further implement organizational activities, training courses; a reward system and customer service feedback strategies and induce employees to willingly exhibit the loyalty and service delivery expected by the organization(Andrew, 2004)..

Firms should encourage employees to actively propose suggestions for improvement of customer services and willingly exhibit active participation through achieving better service efficiency, higher customer satisfaction rates and maximum revenues.

Reducing staff turnover and retaining key staff has become a core strategic objective for most organizations. This has necessitated the need for better management of people through different contracts (Andrew, 2004). Most of the contracts of employment are either formal or informal. The formal contract is written and sets out employment rights, responsibilities and duties called the terms of the contracts. This contracts typically lay out the wages, bonuses, vacations, medical leaves (including maternity/paternity), stock options, and other benefits and compensation that the worker receives for fulfilling his/her obligations to the employer. 
These obligations are also specified in the contract, as is the case of duration of the work, employee engagement, the authority of the employee, ownership of intellectual property, and dispute resolution mechanisms. These agreements also include termination provisions, and they may also include postemployment confidentiality, non-compete, and non-solicitation clauses. This formal contract governs the relationship between employer and employer formally (Employment Act, 2007).

Although formal contract has tried to highlight areas of legal compliance in the employment relationship, it has not managed to enhance employee relations especially in the medium sized firms. It has only drawn a line of legal compliance but has not facilitated the enhancement of employee relations (Casio, 2010). The employee rarely participates in the making of this formal contract but find an already prepared contract by the employer. This contract has inadequately elicited the virtue of trust, commitment, fairness, creativity and teamwork in medium sized organizations. Formal contract just highlight without practically giving details beyond employment contract as psychological contract does to fill the gap (Barnardin 2010). Formal contract fails to outline the byproduct of fulfillment of contract; that is for high productivity achievement (Casio, 2010).

This has necessitated a shift from formal to informal (psychological) contracts owing to emerging trends in employment relationship like outsourcing, short contracting, multi-tasking and globalization. The notion of the psychological contract was first coined by Argyris (1960) to refer to employer and employee expectations of the employment relationship. They are mutual obligations, values, expectations and aspirations that operate over and above the formal contract of employment (Armstrong, 2006). Rousseau (1989), described psychological contract as reciprocal `exchange of agreements between employer and employee. Failure to meet those expectations can lead to breach or violation which in turn can lead to break up of the employment contract. Many relationships at the workplace have been mauled by turnover of key employees due to poor organization climate.

According to CIPD report (2001), negative relations and further poor organization climate at the workplace may elicit disciplinary action, conflict, stress and burnouts. Organization support through fulfillment of employee needs play an important part in creating the agile enterprise (Maguire, 2002). Fulfilling the psychological contract is an essential part of positive employee relations and further positive organization climate. Unitary theory states that management is the sole source of authority and there organization is the sole source of loyalty. This encourages teamwork and respect of leadership for a common objective. Pluralist view appreciates an organization as a system with interdependent unit's maintained at equilibrium. Pluralism elicits trust within the relationship of employment and further a positive climate due to trust (Cave, 1994).

Violations of the psychological contract by either party cause dissatisfaction or strained employer/employee relationship resulting to poor organization climate. It result to distrust, and a feeling of powerlessness among employees, which often lead them to seek a union to restore equity and fairness in the workplace or to simply leave for another company .Most organizations have become more informal to meet customer needs (Peters, 1993).Violation lead to frustration, anger or resentment which can lead to deterioration in trust, de-motivation, staff turnover, reduction in job satisfaction and decline in organizational commitment. This is happening in all organization whether small, medium or large. (Morrison and Robinson (1997), Robison, (1994). Conflicts and misunderstandings only add to tensions and in turn decrease the productivity of the individual where organizational climate is not cultivated. This bring about by employee dissatisfaction with the job, absenteeism, less concerned of customer delight and less commitment (Carsio, 2010).Large organizations in U.S.A are avoiding negative organization climate by proactively managing employee relations effectively through creating fun in the workplace.(Gomez,2010). Actions that may violate a specific individual psychological contract may be within the norms of the social contract.

Thus, breach of a psychological contract between an employee and employer will be perceived at an individual level (Robinson \& Morrison, 1995; Robinson, Kraatz, \& Rousseau, 1994), whereas violation of the social contract will, most likely, be perceived at an organizational or societal level.

Ehrlich (1994) suggested that a belief in employer reliance entails employer responsibility for providing training and enhancing the skill level of employees. Thus, the ideology of employer reliance creates expectations that the employer is mainly responsible for providing retirement income and substantial health benefits to the employee. Given that beliefs about employment relationships are developed on a societal macro level (McKinley et al., 1998; Rousseau, 1995), individuals may have differing perceptions of employment relationships.

\section{Organization support on Teamwork and conflict resolution:}

Perceived organizational support can help in building teamwork as an effective means of solving conflicts in an organization. The conflict or problem at hand can be subjected to the views of the participants whose solutions to the problem differ. Conflicts are many and may arise from the steps towards achieving of the given a group goal or the members in the team can disagree on the goal itself. According to Russell (2005), 
there is no necessity of the team to solve the problems to be performed by a group of individuals. However, the synchronization of individuals, mutual adaptation and co-operation are necessary for solving problems.

In a good climate team participants adjust, communicate and cooperate (Dey,2003).He argued that without communication and mutual cooperation, teamwork is unsuccessful. The communication used in teamwork can be either verbal or non-verbal. Through teamwork, the management of an organization can establish the goals of the organization regarding specific aspects with the help of teamwork. Effective teamwork can be achieved through motivation of the participants.

Successful teamwork leads to quality work and better organizational operations with increased success at all levels of the organization (Linden, 2002).Many organizations have adopted teamwork in their operations making it to be very valuable.

Teamwork enables organization to overcome obstacles through consultations and sharing of ideas. For success, the team participants must possess some skills and abilities that can enable them to perform their duties pertaining to the tasks of the group. Where such skills and abilities are limited, organizations have to train the employees and impart in them the specific needed skills, Critchley, et al (2007).

\section{Employee Involvement and co-operation in Practice and organization climate}

Marchington (2001) sees employee involvement as a feature of soft rather than hard HRM. In firms with a hard orientation, Marchington (2001) considers that the numbers-driven, cost-cutting mentality reduces involvement to a one-way communication channel aimed at transmitting management decisions and propaganda to staff. This contrasts with organizations that are true believers in employees as their greatest asset where there is a strategic commitment to sharing information and opinions and achieving a workplace culture that meets business needs. Peccei and Rosenthal (2001) examined attempts to engender desirable customer-oriented behaviors among employees in the context of a major change initiative in a retail company. The change programme which assumed that management behavior, job design and values-based training would produce a feeling of empowerment among employees, and that this sense of empowerment would lead to pro-social customer-oriented behaviour. A large-scale employee survey showed that staffs who took a positive view of management behavior and who had also participated in value-based training were more likely to feel empowered. In turn, Peccei and Rosenthal (2001) found a positive relationship between positive organization climate and customer-oriented behavior.

Perceived Organizational Support (POS) is the degree to which employees believe that their organization values their contributions and cares about their well-being and fulfills employees' socio-emotional needs (Dean, P. B. 1996). POS is generally thought to be the organization's contribution to a positive payback dynamic with employees, as employees tend to perform better to reciprocate received rewards and favorable treatment. This idea bloomed from Eisenberger and Rhoades' organizational support theory (Eisenberger, 1986). Such POS would increase employees' felt obligation to help the organization reach its objectives, increase their identification with the organization, and contribute to their expectation that improved performance would be rewarded. Behavioral outcomes of POS would include increased in in role and extra-role performance, increased organizational commitment, and decreased withdrawal behaviors such as turnovers and absenteeism. When employees perceive that they are receiving fair treatment in comparison to their coworkers, they perceive more support (Eisenberger, 1986).

Organizational rewards and job conditions play a large role in perceived organizational support as well. Sometimes, extrinsic motivation can mean more to an employee than the intrinsic one because perceived appreciation has the power to turn a bitter employee into a content employee. Eisenberger and Rhoades discuss the many ways that employers can show appreciation and reward their employees which include among others, paying their employees fairly(Eisenberger, 1986) recognizing their employees for new ideas, exceptional work, etc.; promoting their employees when they deserve it; providing job security as incentive to remain with the organization; encouraging autonomy to correspondingly increase production and morale; reduce stress when made aware of it; and to provide proper training, to ensure employees' confidence in their jobs (Eisenberger, 1986). Some of these factors carry less weight than others do. Being autonomous increases an employee's desire to continue to remain loyal to his or her organization because if he feels competent and confident in his ability to do well, he will be less likely to give up or lose faith.

There are many possible consequences of POS discussed in Eisenberger and Rhoades's analysis of studies done on POS (Eisenberger, 1986). The first is organizational commitment like affective commitment, continuance commitment, and normative commitment (Levy, 2013). Affective commitment, or feeling an emotional tie to one's organization, is important in employees because it demonstrates a deeper meaning for work than simply earning money. Continuance commitment, or knowing that staying with one's organization will be less costly in the end than leaving, is telling of extrinsic motivation to remain wherever one will profit the most. Normative commitment or feeling compelled to stay because everyone else is. Some other 
consequences of POS include changes in withdrawal behavior, the desire to remain, strains on employees, performance, job related affect, and job related involvement, Dean (1996).

POS can be positive if reciprocation of support and respect occurs between employer and employee. If the reciprocation does occur and the employee feels that he or she is being appreciated and respected for the work that he or she is doing, the POS is increased, Dean (1996).If the respect and appreciation is either not present or is not expressed adequately, then the employee may begin to harbor suspicion, which may increase organizational cynicism (Eisenberger, 1986). Organizational commitment may, at that point, be lessened; thus jeopardizing the stability of the organization. Reciprocation can include a wide array of things, such as pleasing pay and benefits, a promotion, mutual respect between employer and employee(Levy,2013)..

\section{Effects of organization climate on performance}

According to an experiment done by a group led by Wayne Hochwarter, there is a non-linear relationship between POS and performance (Levy, 2013). Predicted was that high POS was correlated with high performance. Of course, perfect correlations happen infrequently.

Just as POS does not always positively correlate with performance, neither does job satisfaction (Eisenberger, 1986). Although POS probably does have an effect on many employees' performance, it does not necessarily cause performance to increase or decrease in productivity.

A low perception of organizational support can result in employees being wary of reciprocation. Reciprocation wariness can be caused by events that are perceived as not being beneficial to the employee, for example, not receiving payment seemed necessary, or not receiving a good payment for the appropriate length of time (Levy, 2013). According to Lynch and Armeli, fewer companies today than in the past implicitly guarantee long-term employment, provide generous pay increments and comprehensive health benefits, or subsidize general education courses. Examples like these are possible sources for reciprocation challenge amongst employees, potentially lowering their perceptions of organizational support (Eisenberger, 1986).

\section{Socio-emotional factors and organization climate}

The above is just as important in employee health as it is in non-work related circumstances. It is important for post to be high because an employee's feeling of belonging, respect, and support raises his or her morale, which has a positive effect on performance. It is similar to the feeling of support from family and friends (Eisenberger, 1986). However, although each employee most likely has some need to be fulfilled, those needs are not necessarily all the same. It is all relative. Also, some employees might need more support than others. Some might have higher socio-emotional needs. The employee who has higher socio-emotional needs tended to need more approval, esteem, emotional support and produce more when their POS was high (Eisenberger, 1986).Accordingly, strain is affected by POS. When POS is low, strain tends to be perceived in greater intensity. When POS is high, strain is generally perceived as lower, even if it is just as present Dean (1996).

\section{Teamwork in workplace}

Margerison and McCann (2005) define a team as a group of people carrying out work collectively. Success in the work done is achieved if a good team is chosen. In course of executing duty, the individual members of a group that forms a team should have a common goal towards success. The qualities of a good team are capable, intelligent, communicative individual with a clear understanding of the problem at hand would like to cooperate in order to solve the problem as a team. The team should achieve the intended goal as a team and not as individual members of the team. This can only happen in good organization climate supported by the organization itself as a path to success (Levy (2005).There is a connection between teamwork and looking for ideas such as problems and conflict solving ideas. These factors are interconnected and dependent on each other and therefore cannot be separated. In this regard, communication and cooperation are common and present everywhere. A team performs their tasks with creativity, purpose and meaning. People want responsibility when it is given to them with trust. To build organization climate of workplace teamwork, organization must "let go and let God" as the old saying goes. It's important to give the team the skills to cope and perform in difficult situations, and the confidence that they have your trust to succeed (Boland, 2007).

\section{Supervisor Support Has Been Found To Have a Positive Impact On Organization Climate}

A research by Litwin and Stringer at Harvard University indicated that 50 to 70 per cent of an organization's climate can be traced to its leadership or management style. In other words, good managers create good climates, while poor managers create poor climates. Both affect performance. This is said to be true in all sectors of the economy, large or small. To understand the climate that one creates as a manager, he/she need to ask him/her need to ask some basic questions, Litwin (1998). 
1. Do the people in my team feel encouraged to do their best?

2. Do I recognize them when they do perform well?

3. Do they understand what i expect of them and why?

4. Do I give them clear feedback so that they know when they are doing well?

Research has shown that Leaders who use styles that positively affect the climate had better financial results than those who did not; Studies have shown that leaders who have mastered four or more styles (esp. the authoritative, democratic, affiliate and coaching styles) have the very best climate and business performance. The leader can detect the climate they display through the following areas (Michele, 2011)

\section{Flexibility}

In a positive climate, new ideas are accepted easily and unnecessary rules are kept to a minimum. Supervisor by focus is on getting the best people together to do a job, rather than establishing long lines of authority. To improve this dimension, a manager need to reduce the number of regulations and the amount of red tape, encourage employees to come up with new ideas and establish a structure with minimum lines of authority.

\section{Responsibility}

Employees tend to be more motivated when they are allowed by their supervisor to accomplish tasks without constantly seeking their managers' approval. To improve this dimension, it is important for the supervisor to delegate as many tasks as possible to employees and to hold them accountable for the outcomes. They should also be encouraged to take calculated risks without fear of blame.

\section{Standards}

In a poor organizational climate, management places little emphasis on improving performance. Managers need to set challenging but realistic goals, give regular feedback and make sure that performance measures are adequate and clear. Individual employees should be given plenty of opportunity to take part in the goal-setting and planning process.

\section{Rewards}

A positive organizational climate is one in which employees are recognized and rewarded for good performance. To improve this aspect of an organization's climate, managers need to use encouragement more often than they use threats or criticism. The promotion system should help the best people rise to the top and the rewards offered should be in direct proportion to the quality of employees' output. Development opportunities should be used to both reward and improve performance.

\section{Clarity}

People rarely give their best when they are not sure what they are expected to do. It is important for managers to make sure that employees know exactly what is expected of them and how they can contribute to the organization's goals. Policies, procedures and lines of authority should also be clear.

\section{Team commitment}

People need to be loyal to the organization and proud to belong to it. In most roles, they need to be able to co-operate with others in order to get the job done. Managers should make sure they resolve conflicts quickly and foster co-operation between individuals.

\section{Climate and leadership style}

Managers can directly influence their employees' ability to excel by aligning their leadership/management style with the specific demands of the situation they are in and of the people that they work with. When these are out of tune, effort falls away and a bad climate elicit. Managers must be encouraged to develop a variety of leadership styles, since the more styles managers have, the more situations they can manage. That said, research suggests that authoritative and coaching management styles tend to produce positive results in most situations, while coercive and pace-setting styles have to be aligned to specific situations or their impact is usually negative. The affiliate and democratic styles work better if they are backed up by an authoritative style.

To apply these guidelines, individuals and organizations need to become more active in measuring both organizational climate and management style. This will give them hard data about what needs, or does not need, to be changed. Armed with this new understanding, they can begin a developmental journey that will link their own behavior to the bottom-line results of the organization that they hope to lead into the future. Such an 
approach has proved successful for organizations as diverse as Pepsi Co, ICI, The British Army and Unilever. It could prove equally invaluable for your own organization.

A supervisor can create a positive climate by enabling an environment where:

a) There are no unnecessary rules, procedures, policies or practices;

b) Employees are given authority to accomplish tasks without having to constantly seek approval;

c) Challenging but attainable goals are set for the organization and its employees;

d) Employees are recognized and rewarded for good performance;

e) Everyone within the organization knows what is expected of them;

f) People are proud to belong to the organization.

Well-coordinated management policies also promote performance of customer service behaviors; especially, organizational support is highly effective in organizations that have service-oriented organizational climate. To the service industries, management policies, such as reward systems that effectively reflect service performance (i.e. Employee of the Month), timely assistance from the direct supervisors, supply of peripheral tools that help employees perform services, and regular collection of customer feedback on the services, convey messages to employees that demonstrate how much the organization values customer service and express the organization's expectation on loyalty, service delivery, and participation related, service-oriented organizational citizenship behaviors. Also, a linkage of organizational climate to the evaluation and remuneration system will reinforce employees' identification to the scope of in-role behaviors. When employees sense the support from the organization, they will also exhibit customer service related loyalty, service delivery, and participation service oriented organizational citizenship behaviors. Employees would exhibit loyalty by proactively guarding the rights of the organization, promoting a positive image for the organization and exhibiting an attitude of dedication during the course of service delivery.

As relates diversity, there should be no discrimination(Noe,2008).Manager should take control of this by managing expectations(psychological contracts) through clarity of goals, skills and competences required to achieve this and the values they should uphold.(Amstrong,2006).Large organization pursue this having a strategic plan well documented and referred in some decision making.

Workers want to know whether change is stimulating and interesting or offers an opportunity or is it an affliction. Some organizations believes in employees as their greatest asset where there is a strategic commitment to sharing information and opinions and achieving a workplace culture that meets business needs, Peccei and Rosenthal (2001).

Meeting employees expectations result to good relations, positive organization climate hence less turnover, high performance, trust, teamwork and innovations and enthusiasm (Carson et al,1999). Gomez, (2010) asserts that failure to anticipate and respond to employees feeling may result to failure of a decision. Carsio, (2010) asserts that there is consistent and reliable relationship between organization climate and profitability, productivity, employee retention and customer loyalty.

According to CIPD report (2001), negative climate at the workplace may elicit-disciplinary action, conflict, stress and burnouts which strains employer and employee relationship and further separation.

In large organizations, Unions effectively plays a key role in maintaining employee relations as exemplified through cooperation between parties in the relationship, consultations of union and management. When there are clear channels to resolve problems proactively, fairness is experienced and efficiency is realized (Gomez et al, 2010). Careful management of organization climate has a positive contribution to effective employment relations (CIPD report, 2001).

Having good employee relations means providing a fair and consistent treatment of all employees which has challenged many Human Resources Managers in medium sized firms. Managers must play a key role in building strong employee relations and organization climate through, developing quality procedures and policies that effectively communicate in a timely manner. Supervisors support employees through listening, observing and helping in employee concerns.(Gomez,2010).To develop and sustain good relations, supervisors must keep employees informed of the company's policies and strategies. This brings out new behavior and skills needed (Gomez, 2010).Armstrong (2001) asserts that good organization climate is influenced by economic, social, political, ethical, legal and psychological factors.

Good organization climate bring forth mutual beliefs, perceptions, and informal obligations between an employer and an employee. It sets the dynamics for the relationship and defines the detailed practicality of the work to be done.

It is distinguishable from the formal written contract of employment which, for the most part, only identifies mutual duties and responsibilities in a generalized form.(Guest \&Conway,2002).

According to Creswell (2007), teamwork is essential to the success of any organization. Productive teamwork can energize the entire organization. An organization can succeed if it knows how to select the right team that can work effectively well through cooperation and teamwork. Michalisin, et al (2004) adds that knowing how to select the right members of a team is important because no matter how hard a group might 
work together, without the right people on the job, the team will fail. Teamwork is important for every member of the team including the team leaders and individual members.

\section{Recognition and Supervisor Support}

This is an important part of the success of a team and organization. The team members in employment usually search for recognition. Delarue and De Prins (2004) argue that the management should positively recognize the members of the various teams in the firm. Positive recognition entails recognizing outstanding performance, continued performance, and improved performance.

\section{Positive Feedbacks and Supervisor Support}

The results of employees are measured against the feedback received. Therefore, without feedback, the employees will be unable to measure the results of its efforts. With no feedback, confusion will characterize the activities of a team and make them miss their expectations as they produce so many disappointments. The growth of team/individuals depends on the frequency of feedback concerning the performance of the team.

According to Moreland, et al (1996), feedback should be provided on a regular basis. In addition to the above, there is also the provision of opportunities for employees to grow in a positive climate.

The leader must be effective for performance and completion of the work. The important skills and abilities for successful work are the skills and knowledge necessary to complete the assigns tasks. In particular, Bacon and Blyton (2006) propose the teaching of the self-management and the interpersonal skills. These important skills enhance communication and interpersonal relationship while enhancing performance. The selfmanagement team skills enable employees manage his/her own activities and resources while working within the limits of the organization's duties (Letts, Ryan \& Grossman, 2000).

CIPD, (2004) 'asserts that strategic HR employee relations experts should understanding collective labour law, knowing how representative structures work, awareness of general employment law, facilitation and communication skills, negotiation skills, understanding how to develop trust and respect, personal qualities: objectivity, robustness, confidence to tell senior people what they think, awareness of employee attitudes/feelings and business knowledge Critchley, et al (2007).

In manufacturing for example, it is not only senior managers who need training, but also line managers need training in how to conduct relationships with trade union stewards to create positive climate for union staff. Many managers who have no responsibility for conducting pay negotiations may still have to negotiate with unions on a range of issues. On the other hand, employee relations are now seen to be more about building relationships and developing trust. In this respect, the relationship with trade unions doesn't necessarily differ with other kind of relationships with management, colleagues and/or with employees generally. Negotiation skills are equally relevant to a wide range of relationships (CIPD, 2004).There is more emphasis on direct communication, managing organizational change and involving and motivating staff.

Issues about work-life balance and the war for talent reflect a changing workforce with changing expectations. Employers have to come to terms with these changes by creating a culture of positive organization climate. (CIPD, 2004). Organizations need to engage and involve employees and to build and maintain a positive climate, (Critchley, et al 2007)

Leaders must be proactive, for example, in seeking genuine partnership with trade unions, anticipating change and knowing what is happening in the wider world of work (Ulrich, 1997).Employee relations skills and competencies are still seen as critical to achieving performance benefits through a focus on employee involvement and commitment. Employee relations is seen as strategic in terms of managing business risk both the downside risk of non-compliance with an expanded body of employment law, and the upside risk of failing to deliver maximum business performance (Critchley, et al 2007).A key issue for managers is focus. Are they directing their attention to the issues that will make a real difference to business performance? There's strong evidence that a positive climate for employees will lead to superior economic performance. (CIPD, 2004)

The achievement of business goals and financial returns is increasingly dependent on delivery by frontline employees. This emerges from the operation of a mix of HR/high-performance work practices in the context of a supportive management. It can't be imposed from the top but depends on developing employee security, trust and buy-in to the goals and values of the organization (Johnson, 2004). Maintaining healthy employee relations in an organization is a pre-requisite for organizational success. Strong cultures of employee relations are required for high productivity and human satisfaction. Organization climate generally deal with avoiding and resolving issues concerning individuals which might arise out of or influence the work scenario.

Positive organization climate depends upon healthy and safe work environment, involvement and commitment of all employees, incentives for employee motivation, and effective communication system in the organization. Healthy employee relations lead to more efficient, motivated and productive employees which further lead to increase in sales level (Noe, 2008). 
Good climate signifies that employees should feel positive about their identity, their job as well as about being a part of such a great organization. According to Noe, (2008), when the employees do not behave as per accepted norms of behavior, indiscipline sets in. Absenteeism, change in employee's behaviour, slow performance and grievances are all forms of employee indiscipline. Thus, when the employees fail to meet management expectations in terms of standard performance and behavior, it is referred to as indiscipline. In such cases, it must be ensured by the management that steps should be taken so that employee's behavior is in conformity with the managerial expectations (Aggrwal \& Bhargava, 2007).This may be a product of poor climate.

Similarly, the employees also expect from the management to provide them a safe working environment, fair treatment, proper incentives, participation in decisions, and needs satisfaction. The failure on part of management to meet these expectations is termed as grievance. When the employees fail to meet their own expectations whether in terms of personal goals, career goals, performance, self-respect, etc. it is referred to as employee stress. Excessive workload, insufficient workload, peer pressure, excessive/unreasonable use of authority by the management, lack of promotional opportunities, nature of job, etc. all again lead to employee stress (Noe, 2008).

All the above mentioned organizational factors influencing employees' relation must be carefully tackled. An optimistic approach to strengthen disciplinary culture rooted on shared norms of employees should be adopted. An effective grievance redresses system should be there. Stress management strategies should be followed in the organization (Armstrong, 2001).Employee has expectation of fair and just treatment by the management. Thus, management must treat all employees as individuals and must treat them in a fair manner. Employee favoritism should be avoided. Employees' job should not be monotonous but should be interesting and challenging. This can be done by assigning employees greater responsibilities or indulging them in training programs (CIPD report 2001).

A leader should maintain a continuous interaction with the employees. Keep them updated about company's policies, procedures and decisions. Keep the employees well-informed. Informed employees will make sound decisions and will remain motivated and productive. Also, they will feel as a member of organizational family in this manner. Employees must be rewarded and appreciated for a well-done job or for achieving/over-meeting their targets. This will boost them and they will work together as a team. This brings forth a positive organization climate. Encourage employee feedback. This feedback will make the employers aware of the concerns of employees, and their views about you as an employer (Noe, 2008).

Employees should be given competitive salaries. They should be fairly paid for their talents, skills and competencies. Managers should be friendly but not over-friendly with the employees. Managers should build a good rapport with the employee. The employee should feel comfortable with the manager/supervisor rather than feeling scared (Noe, 2008).

It is the prime duty of the superiors and team leaders to discourage conflicts in the team and encourage a healthy relationship among employees. No individual can work alone. He needs the support and guidance of his fellow workers to come out with a brilliant idea and deliver his level best (Bernardin, 2010). An individual spends his maximum time at the workplace and his fellow workers are the ones with whom he spends the maximum hours in a day. No way can he afford to fight with his colleagues. Conflicts and misunderstandings only add to tensions and in turn decrease the productivity of the individual. One needs to discuss so many things at work and needs the advice and suggestions of all to reach to a solution which would benefit the individual as well as the organization (Bernardin, 2010).

There is so much more to life than fighting with each other. Studies say that a healthy relation among the employees goes a long way in motivating the employees and increasing their confidence and morale. One starts enjoying his office and does not take his work as a burden. He feels charged and fresh the whole day and takes each day at work as a new challenge. If one have a good relation with team members you feel going to office daily. Go out with your team members for a get together once in a while or have your lunch together. These activities help in strengthening the bond among the employees and improve the relations among them (Bernardin, 2010)

If one does not agree to any of your fellow worker's ideas, there are several other ways to convince him. Sit with him/her and probably discuss with him where he/she is going wrong and needs a correction. This way he would definitely look up to you for your advice and guidance in future. He would trust you and would definitely come to your help whenever you need him. One should never spoil his relations with his colleagues because you never know when you need the other person.

Avoid using foul words or derogatory sentences against anyone. Don't depend on lose talk in office as it spoils the ambience of the place and also the relation among the employees (Bernardin, 2010).

One needs to enter his office with a positive frame of mind and should not unnecessarily make issues out of small things. It is natural that every human being can not think the way you think, or behave the way you behave. Counsel the other person and correct him wherever he is wrong. It is of utmost importance that 
employees behave with each other in a cultured way, respect each other and learn to trust each other. An individual however hardworking he is, cannot do wonders alone. It is essential that all the employees share a cordial relation with each other, understand each other's needs and expectations and work together to accomplish the goals and targets of the organization (Bernardin, 2010)

While managing change in the firm, the employee involvement in making sure the change is effected is very important while the management has to ensure that the skills processed by the employees are compatible with those required in the market to meet the customer needs (Bernardin, 2010). With the increased importance of the positive climate, the human resources is has shifted its focus to quality, innovation and reduction of the cost. Employee relations (ER) is better viewed as a long term goal rather than short term because it deals with the way the HRM treats the people in long term view. It thrives best in a positive climate. Today in most industries, the HRM is recognized since it's of big concern to the company since it's not meant to only ensure that the employees comply with the laid down policies but also win commitment of the workers, this therefore makes the relations a worthy investment. HRM strategies are affected or influenced by the decisions made in relation to the structure, strategy and considering the external factors like the legal system, labor market position and the influence of trade unions (Aggarwal \& Bharva, 2008).

Nowadays, employees are often selected and recruited into an organization because of their particular skills and expertise that can assist the organization in attaining high performance standards (Aggarwal \&Bharva, 2008). At the same time as the competition for the best employees increases, managers, human resource Directors, and recruiters are all looking for the right combination of inducements in attracting these individuals, (Bernardin, 2010). Gaining a better understanding of what employee's desire for their employment relationship is essential to the success of these efforts. Accordingly, these are the learning outcomes that are being aimed in this study for finding out whether psychological contracts help or hinder our understanding and prescription for orderly employee relations (Bernardin, 2010).

Change refers to new reporting relationships, responsibilities, procedures, policies, equipment, tools, and/or software used on the job. Here the supervisor must direct how an organization or work unit responds to change as a whole, rather than how individuals respond. (Katz and Kahn, 1978). The supervisor must be a good communicator and the organization needs to put open communication structures in place. Culture describes how things are done in an organization or agency. A leader who Create a learning culture elicit positive climate.

Decision-making is the process used in selecting a solution to a problem, deciding how to allocate funds or resources and how to reorganize work. A leader must have decision making capabilities to guide on positive attitude. Effective supervisor need to delegate duties to elicit a warm climate ideal for employee development. Competencies refer to work related skills and knowledge. Supervisors must match job with individual competences to build a positive climate.

Morale is how an employee feels about him or herself. How good or bad do they feel about their selfimage in relationship to what they do where they work and how they are doing at their place of employment. They are reinforced by the supervisor support and encouragement.

Performance evaluations are formal, written appraisals of an employee's work as well as informal verbal feedback given to employees about work by supervisors or by team members in self-directed work teams. Deviations are corrected by the supervisor given that they set goals together and rewards awarded for surpassing expectations, this creates a positive organization climate.

Quality refers to doing things right the first time. Quality services means meeting the needs, standards, and expectations of clients being served. A supervisor who encourages this throughout the work units creates an enabling environment or a good climate for all to associate with.

Training and development refers to work related educational experiences offered by the organization to its employees to increase their skills and knowledge. The employees feel valued and payback by doing more than the bear minimum.

According to the social exchange perspective, when an employee senses that their contributions to the company are noticed, they may feel obligated to help the organization to achieve the company goals (Eisenberger, Hutchison and Sowa, 1986).Driven by this sense of obligation, employees are more likely to perform not only in-role but also extra-role organizational behaviors (Organ, 1988; Settoon, Bennett and Liden; 1996; Ling and Wang, 2007; Peng, 2007). Client service personnel provide instant services and responses to customers, and perception of such services and responses often have direct influence to customers' overall impression on the organization and their decisions for repeat purchases (Saeed, 1990).

Though it is rather difficult to regulate OCB through formal organizational management systems, substantial control may be achieved through indirect, unofficial methods, i.e. messages delivered by OC (Schneider, White, and Paul, 1998). Recent studies on customer orientation have also put forward that an, organization must first create a work environment that facilitates improvement of employee satisfaction, organizational commitment, and work behaviors before the organization can improve customer satisfaction, quality of service, and customer loyalty (Paulin, Fergusonand Bergeron, 2006; Schneider and Bowen, 1985). 
The reason is that $\mathrm{OC}$ molds the attitudes and behaviors of employees, with which they interact with the peers and customers. It is also possible to change employees 'definitions on the scope of job roles. Schneider et al(2005) indicated that when both the managers' efforts and the internal service environment are working towards creating an OC, this OC will be developed towards customer-oriented service behaviors. OC conveys how important an organization sees certain service behaviors and forms a frame of reference seen by employees as the unchartered norms expected to be observed (Ajzen and Fishbein, 1980); some may even see the extra-role citizenship behaviors as part of their job duties. Therefore, when employees sense that their service behaviors are valued by the organization, a sentiment bearing the context of "repaying the organization "for its support may be formed and an interactive effect of the two factors creates a potential for reinforcement of serviceoriented OCB.

The organization's management should always think strategically as they constantly change the culture of the organization. The leaders are to facilitate, coach and be consensus builders as well as consultants regarding planning and strategic management.

Transformational leadership, which is described as the superior leadership performance that occurs when leaders broaden and elevate the interests of their employees, when they generate awareness and acceptance of the purposes and mission of the group, and when they stir their employees to look beyond their own self-interest for the good of the organization, Jennings (2002.

Supervisor support was found by Eisenberger and Rhoades to be strongly related to employees' perception of support. Typically, people view their employer's actions, morals, and beliefs to be indicative and representative of the organization's actions, morals, and beliefs.

\section{Unitary Theory}

\section{Theories on Organizational Climate}

Organizational climate have theoretical base on relational contracts which are long term and open ended relationship founded within unitary organization in exchange for support, loyalty and trust. In unitary view the management is the sole source of authority and there organization is the sole source of loyalty. This encourages teamwork and respect of leadership for a common objective meaning the leadership is charged with the responsibility of building a positive organization climate that will bear fruits of loyalty and organizational citizenry (Cave, 1994).

\section{Pluralist Theory}

Transactional contracts are short term relationships set within pluralistic organizations and characterized by mutual self-interest. Pluralist view appreciates an organization as a system with interdependent units maintained at equilibrium. Pluralism elicit trust within the relationship of employment(Cave 1994).Understanding and keeping organizational climate is key to success of any organization regardless of whether transactional or relational (Andrew et al, 2004).

Building on the framework introduced by McKinley et al. (1998), employees who are employer reliant believe that the appropriate conduct in employment relationships is support for and care for the employee in terms of providing long-term job security in exchange for loyalty and dedication which a perception of organization support for good climate (Downs, 1995).

\section{Herzberg Theory of motivation Job satisfaction}

Working in a team empowers people and helps them develop autonomy, which is a source of job satisfaction and reduces stress, (Hayes, 2005). The factors leading to job satisfaction corresponds to the employee's need to further his or her qualifications, career and to develop his or her personality ,(Hayes, 2005).Other factors that influence job satisfaction compromises working conditions, wages of employees, the management styles employed and the organization itself. These are denoted as motivators or satisfiers and dissatisfiers which has little influence on positive attitudes to work. Satisfaction is important for employee performance. If teamwork increases employee's job satisfaction, then the productivity of the employee will improve (Ketchum \& Trist, 2002). Chen et al., (2004); Ellis et al., (2005); argue that the skills of a team do not have to be innate. It is possible for team participants to learn the knowledge, skills and abilities necessary for working adequately in a team (Fröbel\&Marchington, 2005). According to Thompson \& Thompson (2009), organizations that have embraced teamwork have record increased performance in productivity at work, issues, and problem solving at work and stimulation of new growth in the organization.

\section{Equity Theory}

The equity theory states that employees feel entitled to what they are given as workers, based on their inputs to the job. Therefore, fairness can be perceived even if the rewards differ in size, based on employee rank. 
Fairness can also be described as unwritten expectation or the fairness of happenings in the organization. The office politics or the promoting of self-interest, are often related to employees perceptions of procedural justice (Eisenberger, 1986).

\section{Conclusion}

Perceived organization climate can be positive if reciprocation of support and respect occurs between employer and employee. If the reciprocation does occur and the employee feels that he or she is being appreciated and respected for the work that he or she is doing, the Perceived organizational climate is increased, Dean (1996).If the respect and appreciation is either not present or is not expressed adequately, then the employee may begin to harbor suspicion, which may increase organizational cynicism (Eisenberger, 1986). Organizational commitment may, at that point, be lessened; thus jeopardizing the stability of the organization. Reciprocation can include a wide array of things, such as pleasing pay and benefits, a promotion, mutual respect between employer and employee (Levy, 2013).

\section{References}

[1] Aggarwal, U. \& Bhargava (2010). Examining Antecedents and Outcomes of Psychological Contract Breach: Mediating Role of trust. Academy of International Business, Rio Janeiro, Brazil

[2] Aggarwal U. and Bhargava, S (2009).The effects of Equity Sensitivity, Job stressors and Perceived organizational Support on Psychological contract Breach, Asia Pacific Management Conference, Thailand.

[3] Aggarwal U. and Bhargava, S (2009).Exploring Psychological Contract Contents in India: the employee and employer perspective, British Academy of Management, London

[4] Aggarwal U. and Bhargava, S (2009), "Examining Mediating Role of Relational Psychological Contract on the relationship between Perceived Organizational Support and Job Engagement "Australia and New Zealand Academy of Management (ANZAM), Sydney.

[5] Aggarwal U. and Bhargava, S (2008), Impact of Job Factors on Psychological contract: the moderating role of personality', Irish Academy of Management , Dublin City.

[6] Aggarwal U. and Bhargava, S (2007). Understanding Stakeholder Expectations from the Psychological Contract framework: An Examination of Relational Psychological contract and Psychological Concepts. Association on Employment Practices and Principles (AEPP), FortLauderdale, Miami, Florida.

[7] Aggarwal U. and Bhargava, S (2007).Garnering Relational Psychological Contract through Organizational Commitmentthe role of Psychological Engagement and Ownership among outsourced Employees. Australia and New Zealand Academy of Management (ANZAM), Sydney.

[8] Aggarwal U. and Bhargava, S (2006). The Role of Human Resource Management in developing Psychological Contract A Perspective. International conference on Cross-cultural issues in human resource Management. Department of Management Studies, Jammu University, J \& K, India

[9] Ajzen I, Fishbein M (1980).Understanding attitudes and predicting social behavior, New Jersey: Prentice-Hall

[10] Alan, P(2008) - Human Resource Management in a Business Context, $2^{\text {nd }}$ Edition,U.K

[11] Andrew R.F, Ani B.R \&Richard H.N-Psychological contract expectations of construction project manager(2004),U.KEmerland Group publishing

[12] Armstrong, M,(2001),Hard book of HRM practice, $7^{\text {th }}$ edition, ,London, Kogan page

[13] Amason A (1996). Distinguishing the effects of functional and dysfunction conflict on strategic decision making: Resolving a paradox for top management teams.

[14] Armstrong, M,(2006)Hard book of HRM practice, $10^{\text {th }}$ edition, ,London,Kogan page)

[15] Anderson JC, Gerbing DW (1988).Structural equation modeling in Practice: A review and recommended two- step approach.Psychol.

[16] Barnadin, J. H (2010),Human resources Management, an experiential approach, $5^{\text {th }}$ Edition, New York, McGraw-Hill

[17] Bell S, Menguc B (2002). The employee-organization relationship, organization citizenship behaviours, and superior service quality.

[18] Bettencourt LA, Brown SW (1997). Contact employees: Relationships among workplace fairness, job satisfaction and pro-social service behaviors.

[19] Bettencourt LA, Gwinner KP, Meuter ML (2001). A comparison of attitude, personality, and knowledge predictors of serviceoriented organizational citizenship behaviors. .

[20] Bitner MJ, Booms BH, Tetreault MS (1990). The service encounter: Diagnosing favorable and unfavorable incidents.

[21] Blau PM (1964). Exchange and power in social life. New York: Wiley.Borman WC, Motowidlo SJ (1993). Expanding the criterion domain to include elements of contextual performance. In: N. Schmitt and WC.

[22] Boddy, John.Negotiating the 'psychological contract.Training Journal, Aug 2000: 10. Jenna Pickup

[23] Carsio, F. W(2010),Managing Human Resources, Irwin, New York McGraw-Hill

[24] CIPD Survey report (2001), Employer perceptions of psychological contracts, ,London short run press

[25] Cobb, S. ( 1976). Social support as a moderator of life stress. Psychosomatic Medicine

[26] Conway, Neil \&Briner, Rob B(2005). Understanding Psychological Contracts at Work: A Critical Cropanzano, R.S. \& K.M. Kacmar (Eds.). Organizational politics, justice, and support: Managing the social climate of the workplace, 149-164. Westport, CT: Quorum Evaluation of Theory and Research. Oxford, UK: Oxford University Press

[27] Cullinane, Niall and Dundon, Tony. "The psychological contract: a critical review", International Journal of Management Reviews, 8(2): 113-129 (2006)

[28] Feldheim, Mary. Downsizing. Paper presented at the Southeastern Conference of Public Administration, St. Petersburg, FL, October 6-9 (1999).

[29] Dimitriades ZS (2007). The influence of service climate and job involvement on customer-oriented organizational citizenship behavior in Greek service organizations: A survey on Employee Relations.

[30] Eisenberger R, Fasolo P, Davis-La MV (1990). Perceived organizational support and employee diligence, commitment, and innovation. . 
[31] Eisenberger, R., Huntington, R., Hutchison, S., \& Sowa, D. 1986.Perceived organizational support. Journal of Applied Psychology

[32] Dean, P. B. (1996). Organizational Cynicism. Academy of Management Review ,Vol 23, No. 2, 341-352.

[33] Equity Theory. (2004, April 15). Retrieved February 22, 2013, from Wikipedia: http://en.wikipedia.org/wiki/Equity_theory/

[34] Levy, P. E. (2013). Industrial/Organizational Psychology, 4th Edition. In P. E. Levy, Industrial/Organizational Psychology, 4th Edition New York, NY: Worth Publishers.

[35] Byrne, Z. Hochwarter, W. (2008) "Perceived organizational support and performance: Relationships across levels of organizational cynicism", Journal of Managerial Psychology, Vol. 23 Iss: 1, pp.54 - 72

[36] Fasolo PM (1995). Procedural justice and perceived organizational support: Hypothesized effects on job performance. In Cropanzano RS, Kacmar KM (Eds.), Organizational politics, justice and support: Managing the social climate in the workplace. . Westport, CT:Quorum Books.

[37] Flippo,E.B, (1984) Personnel management, $6^{\text {th }}$ Edition,),New York McGraw-Hill

[38] Guest, David E. "Is the psychological contract worth taking seriously?" Journal of management

[39] Guest, D. (2004). "The psychology of the employment relationship: An analysis based on the psychological contract". Applied Psychology: An International Review

[40] Guest, D. and Conway, N. (2004).Employee Well-Being and the Psychological Contract. London:

[41] George JM ( 1990). Personality, affect, and behavior in groups.

[42] George JM ( 1991). State or trait: Effects of positive mood on pro-social behaviors at work.

[43] Graham JW (1991). An essay on organizational citizenship behavior Employee .

[44] Hofmann DA ( 1997). An overview of the logic and rationale of hierarchical linear models.

[45] Hofmann DA, Morgeson FP, Gerras SJ (2003). Climate as a moderator of the relationship between leader-member exchange and content specific citizenship: Safety climate an exemplar. .

[46] Hogan J, Hogan R, Busch CM (1984). How to measure service orientation.

[47] Hsu SW, Lin LL, Chang HH (2010). Study of transformational leadership, service climate and service-oriented citizenship behavior of cabin attendants in the international airline. J. Human Res. Manage.

[48] Huang HM (2006). The Effect of Perceived Organizational Support on Service-oriented Organizational Citizenship Behaviors - A Case Study on Carrefour Taiwan. Master Degree Thesis, Graduate Institute of Management Science, Aletheia University.

[49] John C. Edwards \& Steven J. Karau( 2007) Journal of Leadership \& Organizational Studies

[50] Karambu.I,(2003) ,Business daily-Wed $9^{\text {th }}$ March 2011-Employee wellness.

[51] Kao RH (2008). The relationship between leader behaviors, organizational climate, and quality of services - A case study of Kaohsiung Harbor Police Bureau, J. Human Res. Manage.

[52] Katz D, Kahn RL (1978). The social psychology of organizations. New York: Wiley.

[53] Koys DJ ( 2001). The effects of employee satisfaction, organizational citizenship behavior, and turnover on organizational effectiveness: A unit-level, longitudinal study. Personnel Psychol., 54: 101-115.

[54] Ling C, Wang CH (2007). Organizational climate and service-oriented human resource management strategies, Modern Manage. Sci., 5: 3-4.

[55] Lester, Scott W; Kickul, Jill. (2001). "Psychological contracts in the 21st century: What employees value most and how well organizations are responding to these expectations". Human Resource Planning, .

[56] Lin YZ (2003). Service Marketing, Taipei: Excellent Enterprise Co., Ltd.

[57] Lynch, P. D., Eisenberger, R., \&Armeli, S. (1999). Perceived organizational support: Inferior versus superior performance by wary employees. Journal Of Applied Psychology.

[58] Moorman RH ( 1991). Relationship between organizational justice and organizational citizenship behavior: Do fairness perceptions influence employee citizenship? J. Appl. Psychol., 76: 845-855.

[59] Moorman RH, Blakely GL, Niehoff BP (1998). Does perceived organizational support mediate the relationship between procedural justice and organizational citizenship behavior? Acad. Manage. J.41(3): 351-457.

[60] Morrison EW (1994). Role definitions and organizational citizenship behavior: The importance of the employee's perspective. Acad.Manage. J. 37(6): 1543-1567. Noe, R. A(2008), Gaining competitive advantage, New York McGraw-Hill

[61] Organ DW (1988).A restatement of the satisfaction-performance hypothesis.

[62] Reed, A(2004). Innovation in Human Resources Management; tooling up for talent war, ,MumbaiJaico House Rhoades, L., \&Eisenberger, R. 2002Perceived Organizational Support website

[63] Parasuraman A (1987). Customer-oriented corporate cultures are crucial to services marketing success. J. Serv. Mark., 1(1): 3946.

[64] Parasuraman A, Zeithaml VA, Berry LL (1988). SERVQUAL: A multiple-item scale for measuring consumer perceptions of service quality. J. Retail., 64(1):12-40.

[65] Paulin M, Ferguson RJ, Bergeron J (2006). Service climate and organizational commitment: The importance of customer linkages.J. Bus. Res., 59(8): 906-915.

[66] Peng GT, Gao YC, Lin ZC (2006). Common Method Variance in Management Studies: The essence, influence, testing, and remedies of questions. J. Manage. 23(1): 77-98.

[67] Peng YP (2007). Exploration of the service-oriented organizational behaviors of university librarians: from the perspective of service quality. J. Librarianship Inform. Stud., 60: 49-65.

[68] Podsakoff PM, MacKenzie SB (1997). The impact of organizational citizenship behavior on organizational performance: A review and suggestions for future research. Hum. Perform., 10: 133-151.

[69] Podsakoff PM, Organ DW (1986). Self-reports in organizational research: Problems and prospects. J. Manage.: 531-544.

[70] Rhoades L, Eisenberger R (2002). Perceived organizational support: A review of the literature. J. Appl. Psychol., 87(4): 698714.Lin and Lin 595

[71] Rousseau DM (1985). Issues of level in organizational research.In Cummings LL and Staw BM (Eds.), Research in organizational behavior. . Greenwich, CT: JAI Press.

[72] Rousseau, D. M (1996).. Psychological Contracts in Organizations: Understanding Written and Unwritten Agreements. Newbury Park, CA: Sage(1998).Organizational Behavior

[73] Sturges, J. and Guest, D. (2004). "Working to live or living to work? Work/life balance early in the career". Human Resource Management Journal, 14, 4, 5-20.

[74] Saeed K (1990). Government support of economic agenda in the developing countries, a behavioral model. World Dev., $18(6)$ : 35.

[75] Schneider B (1980). The service organization: Climate is crucial. Organ.Dynam., 9(3): 52-56. 
[76] Schneider B (1990). The climate for service: An application of the climate constructs. In: Schneider B (Ed.), Organizational climate and culture,383-412. San Francisco: Jossey-Bass.

[77] Schneider B, Bowen DE (1984). New service design, development and implementation and the employee. In George WR, Marshall CE(Eds.), Development new services. 82-101. Chicago: Am. Mark.Assoc.,

[78] Schneider B, Bowen DE (1985). Employee and customer perceptions of service in banks: Replication and extension. J. Appl. Psychol., 70: 423-433.

[79] Schneider B, Bowen DE (1992). Personnel/human resource management in the service sector. In Rowland KR and Ferris GR (Eds.), Research in personnel and human resources management.10: 1-30. Greenwich, CT: JAI Press.

[80] Schneider B, Bowen DE (1993). The service organization: Human resources management is crucial. Organ. Dynam., 21: 39-52.

[81] Schneider B, Bowen DE (1995).Winning the service game. Boston, MA:Harvard Business School Press.

[82] Schneider B, Ehrhart MG, Mayer DM, Saltz JL, Niles-Jolly K (2005).Understanding organization-customer links in service settings. Acad.Manage. J. 48(6): 1017-1032.

[83] Schneider B, White SS, Paul MC (1998). Linking service climate and customer perceptions of service quality: Test of a causal model. J.Appl. Psychol., 83(2): 150-163.

[84] Settoon RP, Bennett N, Liden RC (1996). Social exchange in organizations: Perceived organizational support, leader-member exchange, and employee reciprocity. J. Appl. Psychol., 81: 219-227.

[85] Shadur MA, Kienzle R, Rodwell JL ( 1999). The relationship between organizational climate and employee perceptions of involvement: The importance of support. Group Org. Manage. 24(4): 479-503.

[86] Shore, L.M. \& Shore, T.H. (1995). Perceived organizational support and organizational justice

[87] Shore LM, Wayne SJ (1993). Commitment and employee behavior: A comparison of affective commitment and continuance commitmentwith perceived organizational support. J. Appl. Psychol., 78: 774-780.

[88] Stamper CL, Van DL (2001). Work status and organizational citizenship behavior: A field study of restaurant employees. J. Organ. Behav, 22(5): 517-536.

[89] Torrington, D; Taylor, S; Hall L(2001).,Human Resources management, $7^{\text {th }}$ edition, Prentice Hall, Pearson Edu., (London).

[90] Van DL, Ang S (1998). Organizational citizenship behavior of contingent workers in Singapore. ..

[91] Van DL, Graham JW, Dienesch RM (1994). Organizational citizenship behavior: Construct redefinition, measurement, and validation.

[92] Van DL, Jehn KA, Cummings A (2002). Different effects of strain on two forms of work performance: Individual employee sales and creativity.J. Organ.Behav., 23(1): 57-74.

[93] Venkatachalam, M. (1995). Personal hardiness and perceived organizational support as links in the role stress-outcome relationship

[94] Wayne SJ, Shore LM, Liden RC (1997). Perceptions of organizational support and leader-member exchange: A social exchange perspective. .

[95] Weng LC, Lai YZ, Li YJ (2010). Too much of a good thing: The curvilinear relationship between leader-member relationship and service-oriented organizational citizenship behavior,

[96] Williams, R and Fletcher, C (2001). Performance Management, Job satisfaction, and organization commitment, British Journal of Management, Vol 7:169-179 http://laboursolutions.com/psychological/contract-visited on March 22nd, 20 